\title{
3D SURVEYING AND MODELLING OF ROMAN MONUMENT WITH ARCH
}

\author{
I. Giannaris*, M. Gerotziafa, M. Prantsidi, E. Karachaliou, E. Stylianidis \\ School of Urban-Regional Planning and Development Engineering, Aristotle University of Thessaloniki, GR 54124 - \\ gianioan@plandevel.auth.gr, mayagero1997@gmail.com, m.prantsidi@gmail.com, ekaracha@ plandevel.auth.gr; sstyl@auth.gr
}

\section{Commission II, WG II/8}

KEY WORDS: cultural heritage, Roman, photogrammetry, 3D surveying, modelling

\begin{abstract}
:
Preventive actions of cultural heritage could be carried out using photogrammetry and computer vision techniques. Structure from Motion (SfM) techniques have been proved to be one of the best solutions for the cultural heritage field in terms of cost, time, accuracy and quality. The current work uses a commercial SfM - based software to generate orthoimages of the Arch of Galerius in Thessaloniki, Greece. This is part of students' project in the framework of an undergraduate course in the School of Spatial Planning and Development, Thessaloniki, Greece, to investigate the status of the Roman monument.
\end{abstract}

\section{INTRODUCTION}

Over the last decades, innovative 3D digitisation and geomatics technologies has entered the field of cultural heritage, mainly in order to meet the needs of preservation, management and protection. According to Gomes et al., 2014, the main objectives are to:

- ensure that the information regarding the significant historical characteristics (shape, appearance) of a cultural heritage entity will be reserved in case of natural or other damages

- allow the dissemination of digital representations i.e.

for virtual museums purposes

- uncover art forgery

- collect and study information that is difficult to perform it in the real object

In fact, orthoimages being generated with photogrammetry techniques serve as valuable product in architecture as well as in the preservation of cultural heritage monuments and sites. They provide a metric solution, which allows the combination of radiometric information with real measure and thus a complete representation from every point of view (both terrestrial and aerial) of the documented object (Chiabrando et al., 2015).

Nowadays, a low-cost photogrammetric method is emerged enabling for high-resolution derivable information. SfM technique requires multiple, overlapping photographs as input to feature extraction and 3D reconstruction algorithms (Nyimbili et al., 2016) (Figure 1). It is perceived ideally for low-budget projects and is mainly used in cultural heritage documentation.

Studies such as those of Chiabrando et al. 2015 and Remondino et al., 2017 confirm that SfM techniques have advanced the image processing approach allowing the process of large image datasets and delivering interesting results in terms of accuracy and quality. Today there are lot of open source and commercial software that employ SfM techniques serving as the best solution for cultural heritage documentation (Chiabrando et al., 2015).

The current work focuses on the use of a commercial SfM based software in order to generate orthoimages of a cultural heritage monument from the late Antiquity in Thessaloniki, Greece and especially of the period of Roman Tetrarchy, the Arch of Galerius, which is now part of modern urban structure of the city.

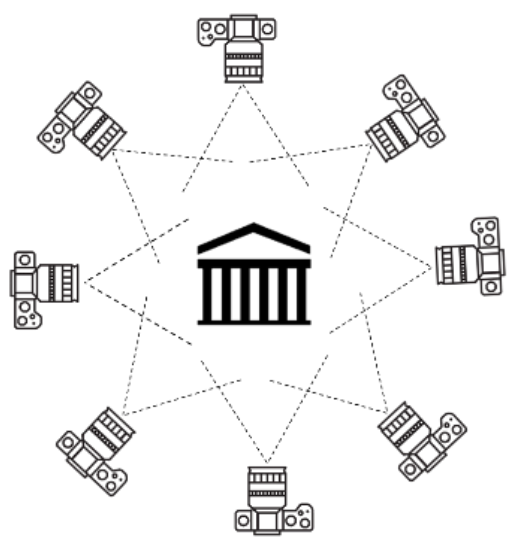

Figure 1. SfM technique

European city centres often include part of cultural heritage monuments among modern buildings and urban structure. Three-dimensional surveys and digital 3D modelling reconstructions can provide accurate and detailed models and images of these cultural heritage sites (Micoli et al., 2018). There have been numerous three-dimensional acquisitions and reconstructions of ancient monuments in Europe in recent years. On the one hand, it is necessary for their conservation and on the other hand contributes to the dissemination, interpretation and presentation of archaeological research as well as brings people into contact with cultural heritage (Athanassiou et al., 2018).

In 2017, Guidi et al., presented a 3D digital reconstruction in time of the ancient Roman Circus of Milan, which is presently covered completely by the urban fabric of the modern city. Part 
of the work included the 3D survey of the remains using both SfM photogrammetry and laser scanning. The generated models were used to validate the archaeological excavations of the past, give the main constraints over which the three-dimensional reconstruction was progressively generated as well as served as elements of proportion towards defining the elevation of buildings highlighted in the historical research but not existing (Guidi et al., 2017).

In addition, the Roman arch of Augusto in Susa went under photogrammetric survey within the work of Chiabrando et al., 2015 aiming to test the results of using different SfM based software. A multi-sensor complete survey of the arch was performed in 2013 resulting in orthophotos and DSMs.
In fact, in 2013 the Ephorate of Prehistoric and Classical Antiquities in Thessaloniki, carried out the 3D digital representation of the Galerian Complex allowing for a virtual tour in the buildings of the complex as it used to be and enabling visitors to better understand the monument's architectural form (Athanassiou et al., 2018).

The current work focuses on the documentation of the Arch of Galerius (Figure 3 \& Figure 4). The Arch of Galerius was built to honor the Caesar, when he returned victorious to the city after his wars against the Persians. The embossed scenes (Figure 5 ) in the two square pillars are arranged in four zones. Each zone represents different events namely chariots, the Roman Emperor Galerius entering the city on horseback while crowds

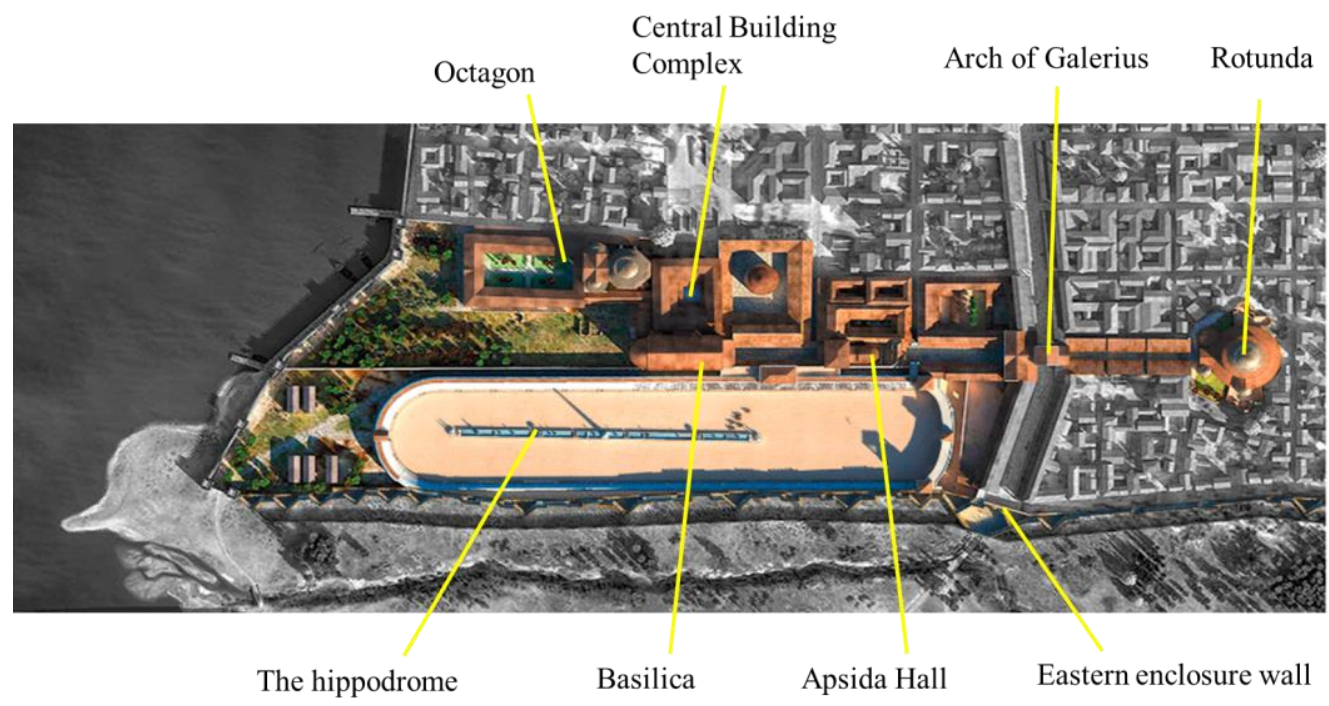

Figure 2. The Galerian Complex (http://galeriuspalace.culture.gr/en/monuments/)

\section{THE MONUMENT}

The Galerian Complex is the most important monumental group in Thessaloniki, Greece. It was built in the late 3rd century-early 4th century $\mathrm{AD}$, when the Caesar Galerius Valerianus Maximianus (293-311 AD) chose Thessaloniki as the seat of the eastern part of the Roman Empire (http://galeriuspalace.culture.gr).

The building complex was incorporated into the city's urban plan, following the layout of its streets, and consisted of the Rotunda, Arch of Galerius, Apsida Hall, Basilica, Central building complex, two storied structure, baths, octagon, the hippodrome, and the eastern enclosure wall (http://galeriuspalace.culture.gr) (Figure 2).

In the second half of the $20^{\text {th }}$ century, significant parts of the complex were revealed during the excavations. It is one of the monuments, which were included in the UNESCO World Heritage List in 1988. In addition, in 2008, the archaeological site received an award from the European Union and Europa Nostra (pan-European Federation for Cultural Heritage) for the exceptional and exemplary restoration and conservation of its ruins, as well as the totality of interventions which transformed an abandoned site into a well-organised, educational one which functions as a pole of attraction in the heart of the contemporary city (http://galeriuspalace.culture.gr). of people welcome him, battles between the Romans and the Persians, victories etc. Today the Arch of Galerius is the best preserved of this period in Europe (Athanassiou et al., 2018) and is situated in one of the most dense-built and busy spots of Egnatia Street in Thessaloniki's city centre.

The Arch of Galerius it is a well-preserved monument of high historical and architectural interest, which has been the subject of study for many scientists. However, it seems that the digital three-dimensional representation of the monument carries some challenges related to its size, structure and historical information. In particular, the acquisition of the embossed scenes and architectural details of the monument requires great precision in in order to successfully render and represent all the information. On the other hand, the big size of the monument and its arch structure call for innovative 3D digitisation and geomatics technologies in order to ensure that the information regarding the significant historical characteristics (shape, appearance) of the cultural heritage entity will be reserved.

In the current work, we use photogrammetry techniques in order to generate orthoimages of the monument's facades. This is part of students' project in the framework of an undergraduate course in the School of Spatial Planning and Development, Thessaloniki, Greece, to investigate the status of the Roman monument. 


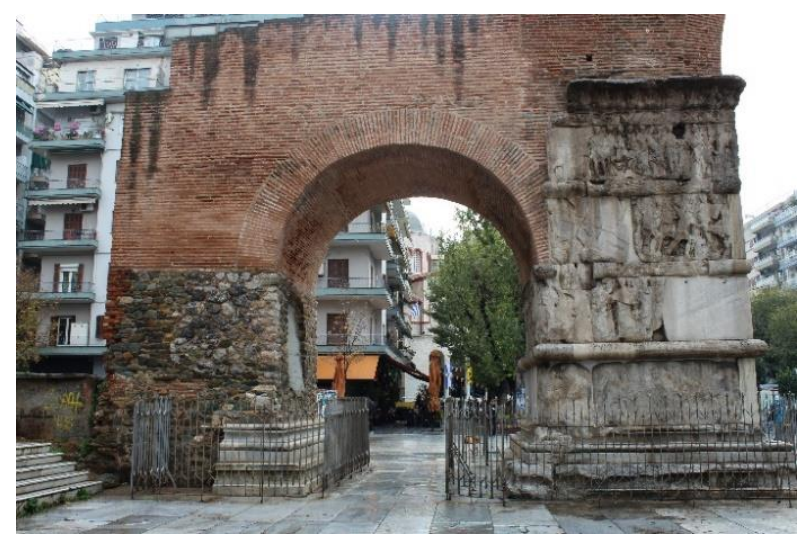

Figure 3. West facade

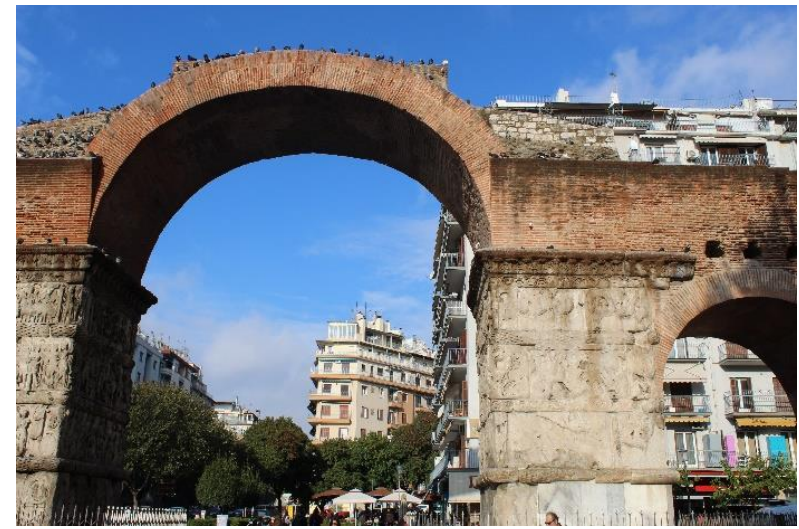

Figure 4. East facade in 2019

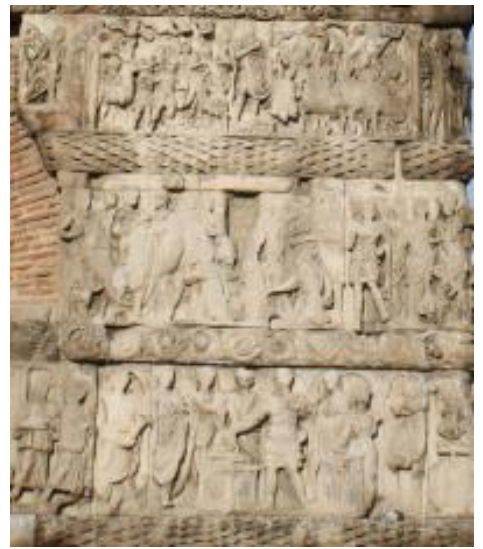

Figure 5. Embossed scenes in the Arch of Galerius

\section{ORTHOIMAGES GENERATION}

\subsection{Equipment and data acquisition}

The data were acquired using the Canon EOS1300D camera (Table 1). A total of 173 photos were captured in 2 strips (1 vertical $\& 1$ oblique - for the facade of the arch in a distance of $6.5 \mathrm{~m}$ from the object and 7 oblique images for each of the arches in a distance of $2 \mathrm{~m}$ (Figure 6). The data acquisition details are presented in Table 2 .
Table 2. Data acquisition details

\begin{tabular}{|l|c|}
\hline Distance & $6,5 \mathrm{~m} \mathrm{\&} 2 \mathrm{~m}$ \\
\hline Focal Length & $20 \mathrm{~mm}$ \\
\hline GSD & 0.0044 \\
\hline Number of Strips & 2 \\
\hline $\begin{array}{l}\text { Total Number of } \\
\text { photos }\end{array}$ & 173 \\
\hline
\end{tabular}

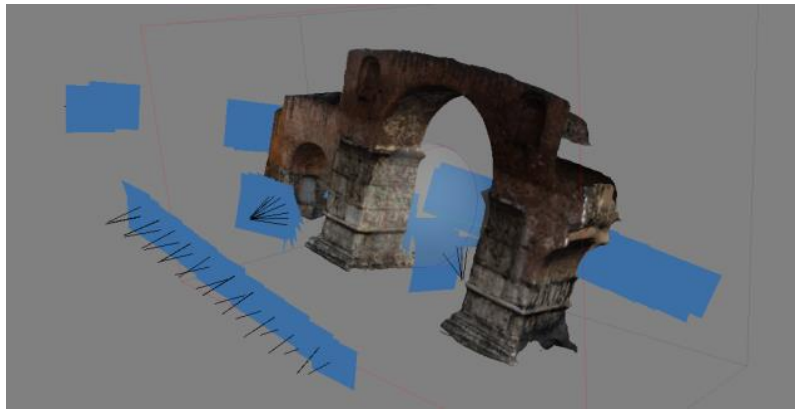

Figure 6. Strips of images captured

For capturing the images, we used the standard configuration of the DSLR camera with autofocus and with no camera calibration. Each image is captured from the same distance from the arch to keep the same scale. In another step of our project we would like to have a calibration test of the camera to calculate the focal length, CCD centre and the lens distortion but in this stage we used the manufacture values.

\subsection{Data processing \& results}

The data were processed in Agisoft Photoscan software. A masking procedure was applied on the images aiming to exclude the background throughout the photo alignment process and produce a less noisy point cloud (Figure 7). Due to the large number of images, and in order to speed up the process, we split our model into different chunks using different images. In order to align and merge the chunks we used images with overlap on the edges. Follow this procedure, the software recognised common points into both chunks and make the alignment easier. Therefore, a textured mesh was produced (Figure 8) and the orthoimages of the facades were generated (Figure 9 \& Figure 10). The generated 3D model was scaled using the dimensions of the fence around the arch.

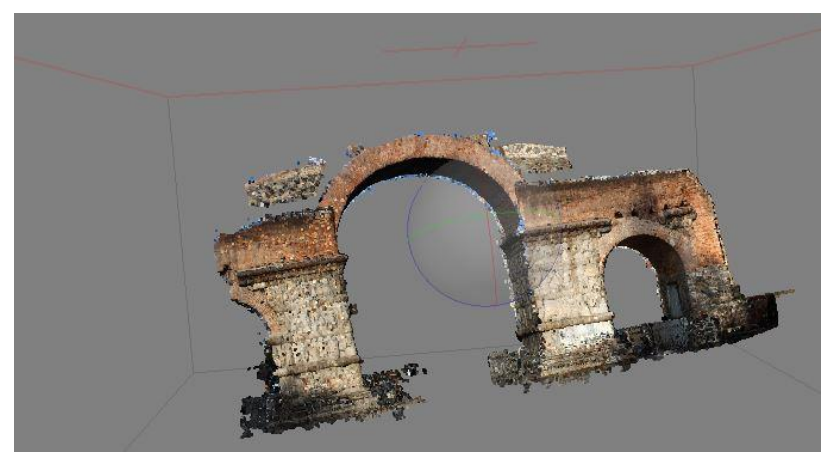

Figure 7. Dense point cloud (east side)

Table 1. Canon EOS1300D specifications

\begin{tabular}{|l|c|}
\hline Sensor & CMOS $18.02 \mathrm{Mp}$ \\
\hline Resolution & $5202 \times 3465$ \\
\hline Focal length & $18-55 \mathrm{~mm}$ \\
\hline Aperture-f & 4 \\
\hline
\end{tabular}




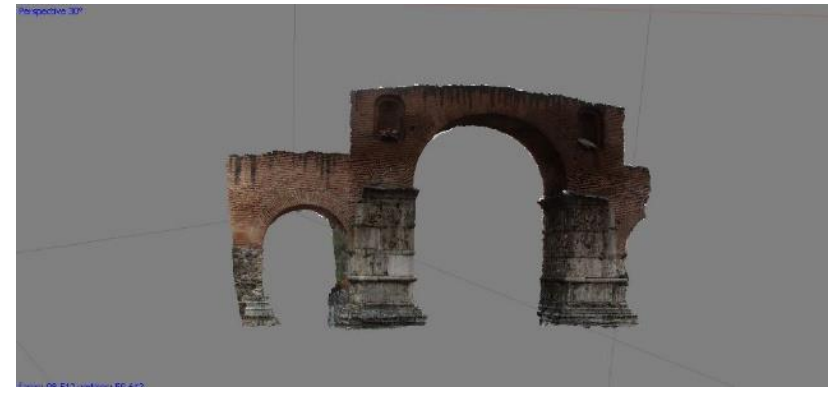

Figure 8. Textured mesh (west side)

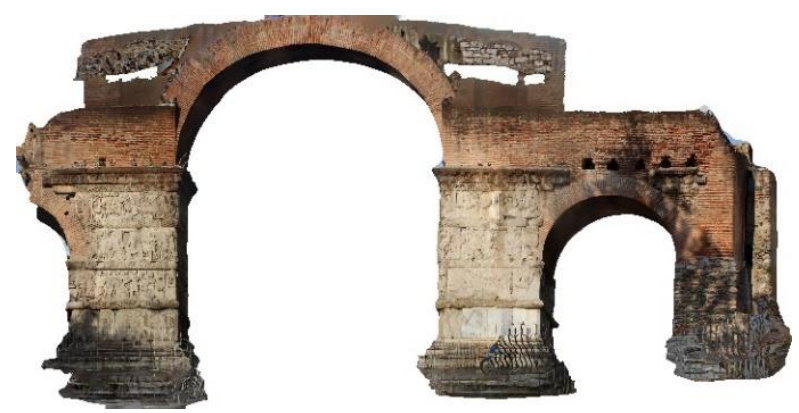

Figure 9. Orthoimage of the east facade

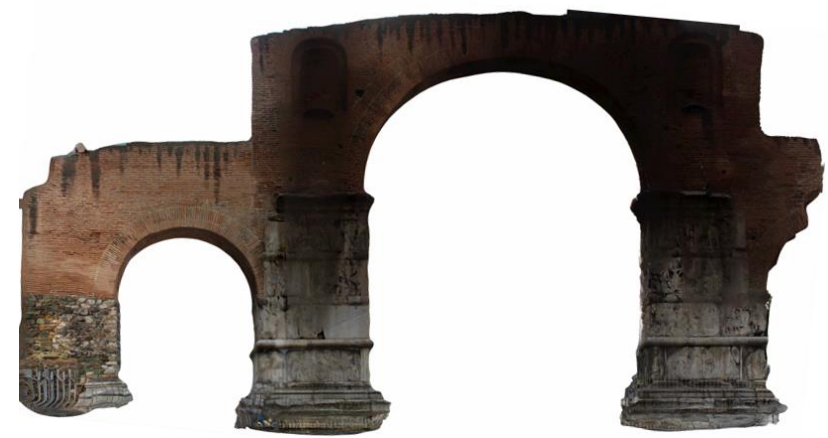

Figure 10. Orthoimage of the west facade

\section{CONCLUSIONS}

The current work presented the generation of orthoimages of a high value cultural heritage monument situated in the centre of Thessaloniki, Greece. By using a commercial SfM based software a number of photos were processed fast and with satisfying results in terms of accuracy and quality.

\section{REFERENCES}

Athanasiou, F., Malama, V.I., Miza, M., Sarantidou, M., 2018. Virtual Access to Underground Galerian Complex - The Hippodrome. Proceedings of the 4th Biennial of Architectural and Urban Restoration (BRAU4), pp. 537-547.

Chiabrando, F., Donadio, E., Rinaudo, F., 2015. SfM for Orthophoto to Generation: A Winning Approach for Cultural Heritage Knowledge. International Archives of the Photogrammetry, Remote Sensing and Spatial Information Sciences, XL-5/W7, pp. 91-98. 10.5194/isprsarchives-XL-5W7-91-2015.

Gomes, L., Regina Pereira Bellon, O., Silva, L., 2014. 3D reconstruction methods for digital preservation of cultural heritage: A survey. Pattern Recognition Letters, 50. Elsevier, pp. 3-14. doi.org/10.1016/j.patrec.2014.03.023.

Guidi, G., Gonizzi, S., Micoli, L., Malik, U., 2017. Accurate Reconstruction of the Roman Circus in Milan by Georeferencing Heterogeneous Data Sources with GIS. Geosciences 7(3), pp. 91. 10.3390/geosciences7030091.

Micoli, L., Gonizzi, S., Malik, U., Guidi, G., 2018. 3D data integration for the digital reconstruction of cultural heritage monuments. IOP Conf. Ser.: Mater. Sci. Eng., 364. $10.1088 / 1757-899 X / 364 / 1 / 012043$

Nyimbili, P., Demirel, H., Seker, D., Erden, T., 2016. Structure from Motion (SfM) - Approaches and Applications. International Scientific Conference On Applied Sciences.

Remondino, F., Nocerino, E., Toschi, I., Menna, F., 2017. A critical review of automated photogrammetric processing of large datasets. Int. Arch. Photogramm. Remote Sens. Spatial Inf. Sci., XLII-2/W5, pp. 591-599. 10.5194/isprs-archives-XLII2-W5-591-2017.

Ephorate of Antiquities of Thessaloniki City, 2019. The Galerian Complex http://galeriuspalace.culture.gr (1 June 2019). 